Revista Destaques Acadêmicos, Lajeado, v. 13, n. 2, 2021. ISSN 2176-3070

DOI: http://dx.doi.org/10.22410/issn.2176-3070.v13i2a2021.2928

http://www.univates.br/revistas

\title{
FESTA AMEJIKIIM DO POVO KANELA DO ARAGUAIA: DIÁLOGOS COMO AÇÃO EDUCATIVA DE SENSIBILIZAÇÃO INTERCULTURAL
}

\author{
Renata Santana Leite ${ }^{1}$, Marcelo Franco Leão
}

\begin{abstract}
Resumo: O povo indígena Kanela do Araguaia é oriundo do Estado do Maranhão, cujas famílias foram dispersas pelo Brasil devido ao massacre provocado pelos confrontos entre índios e fazendeiros no século passado. Muitas destes indígenas atualmente vivem no município de Luciara/MT, na aldeia Nova Pukanu. Atualmente, esse povo tradicional tem buscado resgatar memórias para registrar sua cultura, sendo que muitos destes estudantes e moradores são indígenas. Assim, o presente estudo teve como objetivo promover diálogos culturais com o Povo Kanela do Araguaia, por meio da compreensão da festa Amejikiim, como uma ação educativa para abordar a interculturalidade. O estudo foi desenvolvido desde 2018 por estudantes da sala anexa multisseriada da Escola Estadual Sol Nascente, localizada na zona rural do município de Confresa/MT. Assim, foi proposta a investigação sobre essa manifestação cultural praticada em uma das aldeias do povo Kanela do Araguaia, situada nas margens do Rio Tapirapé. Para compreender este fator histórico, os estudantes presenciaram depoimentos de anciãos da comunidade. Percebeu-se que a festa Amejikim propicia diversão, prazer e fortalecimento cultural. A dança ensina e contempla o indivíduo em seu saber, seus conhecimentos e sua expressão do mundo e dotado de natureza livre típica de uns processos educativos. Logo, esta ação educativa serviu como sensibilização intercultural, pois os estudantes aprenderam com os mais experientes sobre das origens deste povo tradicional e assim respeitar a cultura do outro.
\end{abstract}

Palavras-chave: Cultura. Educação. Povos tradicionais.

1 Graduação em Pedagogia pela Universidade do Estado de Mato Grosso (UNEMAT). Especialização em Ensino de Ciências pelo Instituto Federal de Mato Grosso (IFMT) Campus Confresa. Professora da Rede Estadual de Ensino (SEDUC/MT).

2 Graduado em Licenciatura em Química (UNISC)e em Física (UNEMAT). Pós-graduado em Orientação Educacional(Dom Alberto) e em Relações Raciais na Educação e na sociedade Brasileira(UFMT). Mestre em Ensino (UNIVATES). Doutor em Educação em Ciências (UFRGS). Professor do IFMT Campus Confresa-MT. 


\section{INTRODUÇÃO}

Cada comunidade educativa, inclusive as escolas indígenas, possuem autonomia e competência para escolher os diversos assuntos relevantes, eixos temáticos, que orientarão as suas atividades educativas. Esses eixos escolhidos geralmente indicam caminhos para tratar de assuntos relacionados ao cotidiano das aldeias, bem como das relações com o entorno regional e dos temas nacionais, afinal, vivemos em um mundo globalizado em que todos esses assuntos mantém uma estreita relação e interferem diretamente no plano de vida de cada pessoa da sociedade. De maneira geral, a escola indígena precisa estar atenta para atuar de maneira a fortalecer a cultura indígena, dominar novos conhecimentos, ampliar a autonomia no pensar e levar os estudantes à emancipação intelectual, ou seja, capaz de tornar as pessoas construtoras de uma sociedade mais justa, saudável e feliz.

Associado a esse importante papel atribuído às escolas, um outro aspecto que necessita ser considerado quando se trata da cultura indígena é a valorização das manifestações culturais. Caballero (2018) defende que as manifestações culturais como as festas e demais atividades coletivas consistem em momentos de grande importância para desenvolver o senso de pertencimento em meio a interculturalidade.

Para Melià (2002), um primeiro passo é promover ações de sensibilização sobre a importância da diversidade, do diálogo com o outro, do respeito com a cultura do outro. No entendimento do autor, quando esse exercício ocorre repetidas vezes se criam condições para a construção identidade, baseada na própria diferença, que, por sua vez, é passada para a consciência própria.

Por isso, a escola indígena precisa saber abordar as diversidades culturais na sala de aula e fora dela. Nessa linha de pensamento, suas ações pedagógicas precisam proporcionar o respeito ao outro e valorização das caracteriza étnicas e culturais dessas populações. Indica-se ainda que sejam trabalhados temas fundamentais como o conhecimento dos ritos e costumes, da língua e dos hábitos de cada povo. Assim, a educação indígena necessita lutar contra o preconceito, a discriminação, a opressão e a intolerância e promover a solidariedade entre os povos, a cultura da paz da justiça e da igualdade entre todas as pessoas. Além disso, deve estar vinculada a todas as formas de expressão cultural da comunidade como a língua, os rituais e as arte músicas, pintura, dança.

Nesse sentido, o intuito deste estudo foi elencar uma manifestação cultural de uma comunidade indígena do norte mato-grossense como fonte de estudo para que a escola presencie, compreenda e possa explorar tais manifestações como situação cultural e social de aprendizagem, ou seja, que o registro proposto sirva de fonte de informações para suas ações pedagógicas futuras no enfrentamento de desafios e das especificidades de um povo que busca sua autoafirmação no mundo contemporâneo. 
Cabe ressaltar que ultimamente a comunidade local a própria extensão da escola busca registrar características da cultura desse povo tradicional para que não fiquem perdidas ao longo do tempo. Os mesmos estão compreendendo sua identidade cultural por meio das danças e valorizando e respeitando a diversidade cultural e social.

Considerando todos os fatores supracitados, o problema que norteou essa pesquisa foi: Como contribuir para que os estudantes de uma escola do campo conheçam e registrem características culturais da festa Amejkiim do Povo Kanela do Araguaia e assim respeitem a cultura do outro?

Neste sentido, o presente estudo teve como objetivo promover diálogos culturais do Povo Kanela do Araguaia, por meio da compreensão da festa Amejikiim, como uma ação educativa para abordar a interculturalidade.

\section{REFLEXÕES TEÓRICAS}

Nos estudos realizados por Rodrigues (2016), fica evidente que a escola necessita evidenciar aspectos culturais e aproximar os estudantes das outras culturas, principalmente caso não sejam indígenas, pois ao conhecer a cultura do outro é que será possível apreciá-la e respeitá-la.

Além disso, a própria Lei de Diretrizes e Bases da Educação brasileira (LDBEN), Lei $\mathrm{N}^{\circ}$ 9.394, preconiza a necessidade de estudar as matrizes étnicas brasileiras, ou seja, é preciso que os professores de todas as escolas de Educação Básica oportunizem ensinamentos sobre os povos indígenas brasileiros e suas manifestações culturais no decurso do processo formativo (BRASIL, 1996, Art. 26-A).

Além disso, ao se tratar de povos indígenas, os mesmos possuem direito assegurado de educação escolar específica, diferenciada, intercultural, bilíngue/multilíngue e comunitária, conforme define a legislação nacional que fundamenta a Educação Escolar Indígena. Esses direitos ficam garantidos pela Constituição Federal (BRASIL, 1988), pela Lei LDB (BRASIL, 1996), e pelas políticas nacionais próprias da Educação Escolar Indígena, monitorada pelo Ministério da Educação (MEC), mas garantida sua execução pelos Estados e Municípios.

A Educação Escolar Indígena ocorre em unidades educacionais inscritas em suas terras e culturas, as quais têm uma realidade singular, requerendo pedagogia própria em respeito à especificidade étnico-cultural e linguística de cada povo ou comunidade e formação específica de seu quadro docente observado os princípios constitucionais, a base nacional comum e os princípios que orientam a Educação Básica Brasileira (Art. 50, Res002/2015-CEE).

No sentido de atender as orientações contidas nos documentos oficiais para a educação escolar indígena, para que sejam respeitadas as especificidades 
de cada povo, fica evidente a necessidade de reforçar as manifestações culturais das comunidades indígenas. Assim, o primeiro passo é conhecer o histórico e as características do povo no qual a escola está inserida.

O povo indígena Kanela do Araguaia é remanescente da etnia KrahôKanela, que vivia no Estado do Maranhão. Seu processo de deslocamento para outras regiões territoriais do país ocorreu na segunda década do século XIX, motivados pela expansão agropastoril que, de certa maneira, expulsou os indígenas do território de origem, conhecida como Morro do Chapéu, que fica localizada no município de Barra do Corda/MA (SOUZA, 2009).

Ainda de acordo com a autora supracitada, foi no início do século XX, que o povo Kanela se dispersa pelas regiões Norte e Centro-Oeste do Brasil, sendo que boa parte da etnia estabelece a Mata Alagada, hoje pertencente ao Estado do Tocantins, como seu território tradicional. Porém, em 1977 os Kanela foram expulsos novamente de seu território pela Companhia e Cervejaria Brahma, que alegou ser a legítima proprietária daquela terra. Desde então, este povo tradicional foi disperso para diversas regiões. A FUNAI "deslocou um grupo composto por cerca de sessenta e cinco pessoas e liderado pelo cacique Mariano para o Parque Indígena do Araguaia, na Ilha do Bananal, território dos povos Javaé, Karajá, Ava-Canoeiro e de um grupo isolado conhecido como Cara Preta" (SOUZA, 2009, p. 95).

Apesar de enfrentar muitos problemas, a cultural do Povo Kanela utiliza de recursos e de linguagem própria, ou seja, não foi totalmente perdida. A forma do povo Kanela expressar sua cultura precisa ser respeitada, mesmo que nem sempre seja compreendida, principalmente pelo não indígena. Manifestações culturais, como a dança, por exemplo, permitem compreender saberem naturais e culturais, ou seja, diferentes maneiras de resolver um conflito, experimentando sensações, lidam com diferentes sentimentos e aprendem a cooperar vivendo em comunidade com um grupo social próprio indígena.

Nesse caso, o povo Kanela do Araguaia utiliza de suas danças, rituais e crenças para expressar sua cultura, mesmo enfrentando os diferentes contextos e situações que vivenciaram. Assim, o povo vai criando e recriando seus costumes, crenças, mitos e forma de vida. Por outro lado, ao conhecer tais manifestações deste povo tradicional, as pessoas não indígenas desenvolvem o pensamento crítico, exercitando o respeito e superando a imaginação simbólica.

Cabe ressaltar que o povo da etnia Kanela do Araguaia permanece instalado no mesmo lugar, pois esses acreditam que a possibilidade de conquistar uma educação é bem viável e real, e a cada novo embate proposto eles saem mais convictos de que sua comunidade é forte, que tem sua cultura viva e por isso precisa ser valorizada. Essas valorizações das manifestações culturais também são propicias para o fortalecimento das comunidades do campo, segundo Arroyo (2007). 
Um exemplo de manifestação cultural do povo Kanela é a tradicional festa nomeada como Amejikiim. Ela propicia diversão, prazer e até desprazer, a dança ensina e contempla o indivíduo em seu saber, seus conhecimentos e sua expressão do mundo e dotado de natureza livre, propícia para o processo educativo. Sim, essa manifestação cultural pode contribuir para a educação, uma vez que a festa pode ser conhecida, respeitada e vivenciada no ambiente escolar, envolvendo a comunidade. Assim, ocorre uma verdadeira troca entre a cultura deste povo, a comunidade e a escola, que é uma instituição que pode valorizar e fortalecer a cultura regional.

Enquanto desenvolver suas danças vai criando e recriando e desenvolvendo, o seu pensamento crítico exercitando a imaginação simbólica, instrumento que lhes fornece os meios de assimilar o real aos seus desejos e ao seu interesse, algo que Lins, Figueiredo e Cavalcanti (2017) também defendem para a educação do campo. Como reunir dentro da mesma situação a cultural e o social.

Segundo Campigoto, Schörner e Novak (2012), as festas e os rituais precisam ser considerados como aspectos de um fenômeno ligado à cultura desse povo. Para os autores, os festejos e ritos culturais, como celebrações religiosas, festejos matrimoniais ou comemorativos e até os próprios encontros de dança são memórias de manifestações culturais carregadas de sentido e permeados por rituais, seja por meio da dança, do canto, da pintura corporal, da comida e bebida que servem ou dos momentos que recordam. Nesse sentido, a defesa por registrar esses momentos para que assim os aspectos da cultura se preservem e esse registro histórico sirva para dar visibilidade à diversidade cultural que temos no Brasil.

\section{PROCEDIMENTOS METODOLÓGICOS}

A presente pesquisa caracteriza-se como um estudo descritivo e exploratório, de abordagem qualitativa. Foi desenvolvido de em julho de 2019. A investigação foi mediada pela professora pesquisadora, juntamente com os anciões e estudantes da sala anexa multisseriada da Escola Estadual Sol Nascente, localizada na zona rural do município de Confresa/MT. Essa intervenção pedagógica teve como intuito promover diálogos culturais do Povo Kanela do Araguaia, por meio da compreensão da festa Amejikiim.

De acordo com Gil (2010), um estudo é considerado exploratório e descritivo quando possui como objetivo principal o detalhamento de ideias, conceitos, concepções ou ainda fenômenos, cujo intuito seja propiciar maior familiaridade com o problema de investigação. Ainda de acordo com o autor, este tipo de pesquisa proporciona levantar as características de um grupo de pessoas, tais como idade, sexo, procedência, nível de escolaridade, concepções, entre outras. 
Com este estudo buscaremos promover uma reflexão entre a proposta legitimada de escola do campo e as percepções dos atores sociais envolvidos com o processo educativo da comunidade pesquisada. Cabe ressaltar que muitos deles são indígenas ou convivem com pessoas da etnia Kanela.

Para esse levantamento de dados, utilizamos a pesquisa de campo, onde visitamos alguns moradores e pais de estudantes para coletar as informações de modo mais espontâneo. Também foram feitas visitas à escola para coletar informações e documentos históricos para análises que nos permitirão finalizar nossas reflexões. Elaboramos um questionário no qual foi perguntado sobre como a escola promove a interação com a comunidade e como os saberes produzidos no ambiente escolar contribuem para o cotidiano do trabalhador do campo.

O primeiro momento da pesquisa foi buscar aporte teórico em obras já publicadas sobre a cultura indígena. O segundo momento foi a coleta de dados, por meio de registrados fotográficos e relatos sobre a festa e a prática cotidiana vivenciadas pelos povos indígenas em sua comunidade e as atividades desenvolvidas na escola, enquanto valorização da Cultura Kanela do Araguaia. No último momento, após a coleta de dados com os investigados, foi realizada a análise desse material, de modo a passar por todas as fases de uma pesquisa, desde a leitura de obras sobre o assunto, registros da dança e coleta de dados com os envolvidos, o que possibilitou a formulação deste texto.

Para dialogar com a proposta da educação do campo enquanto diversidade educacional, buscamos dados com pais, alunos e comunidade de modo geral para compreendermos como a escola tem atendido ao propósito de formação que fortaleça as práticas sociais adotadas na comunidade.

No intuito de garantir o anonimato dos sujeitos participantes, os nomes foram substituídos por codinomes do tipo: mãe do estudante, cacique, ancião, entre outros. Os dados obtidos nas respostas foram interpretados e analisados a luz do referencial teórico utilizado.

\section{RESULTADOS E DISCUSSÃO}

Em julho de 2018, aconteceu na aldeia Nova Pukanu a festa Amejikiim, na qual os indígenas fizeram seus rituais, em que sobre seus corpos foram pintados símbolos significativos, geralmente relacionados com a natureza e com os valores culturais. Também realizaram danças, comidas típicas, competição de arco e flecha, corrida de tora com um percurso de seis quilômetros.

$\mathrm{Na}$ festa Ameijim, mulheres e homens ganham vestimentas e pinturas específicas. As mulheres usam saias de palha de buriti, colares de semente natural e cocar de penas de aves, além de pinturas com tinta de jenipapo. As indumentárias dos homens são mais simples, geralmente constituída por cocar com penas de aves e colar com sementes. Nos homens as pinturas também são com jenipapo. Todas ficam com os pés descalços para ter contato com terra, 
e assim obter uma conexão com o meio ambiente. A festa inicia oficialmente com uma grande celebração na noite anterior das atividades esportivas. Todos participam com trajes típicos, conforme ilustra a Figura 1.

Figura 1: Início da festa Amejkiim na Aldeia Nova Pukanu.

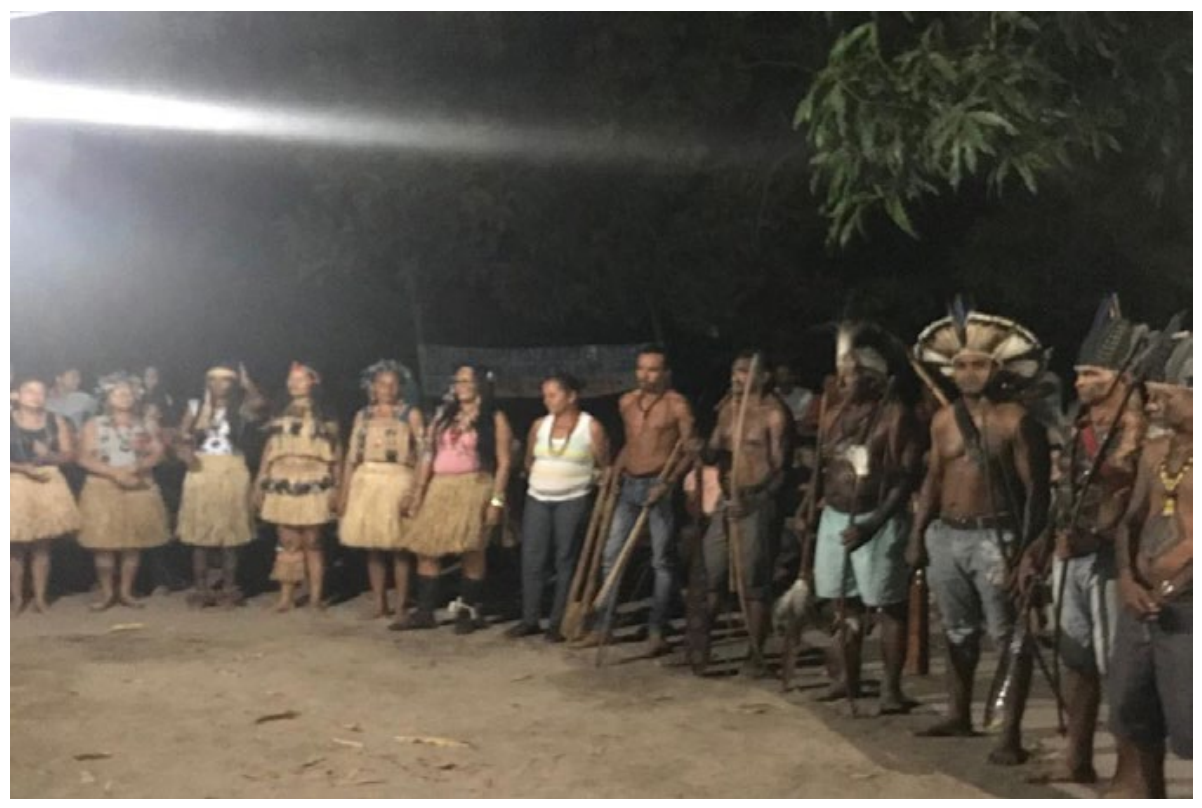

Fonte: Acervo Pukanu (2019).

Como pode ser visto, os Kanela do Araguaia são indígenas que buscam o fortalecimento de suas características culturais como na vestimenta, indumentárias e rituais. Contudo, percebe-se a influência do não indígena neste processo, pois algumas roupas como o jeans são próprias da cultura urbana (SOUZA, 2009).

Muitas destas atividades são exclusivas para os homens, tais como a corrida com tora de madeira. Nesta atividade, as mulheres participam indiretamente dando apoia durante toda a corrida, cantando e batendo o maracá, se posicionam na orla da aldeia, onde permanecem aguardando a chegada dos homens para celebrar juntos. Finalizada a corrida, todos dançam, logo após é preparado e servido um almoço para todos, contendo somente pratos típicos da cultura indígena, nada de comidas industrializadas.

No período da tarde continua a festa com competição de arco fecha, o guerreiro que acerta o alvo te uma pontuação maior e também uma ótima habilidade para caça e pesca para sua própria alimentação. No decorrer da festa ocorrem diversas atividades, como jogos, competições, como ilustrado na Figura 2. 
Figura 2: Ilustração de uma atividade coletiva.

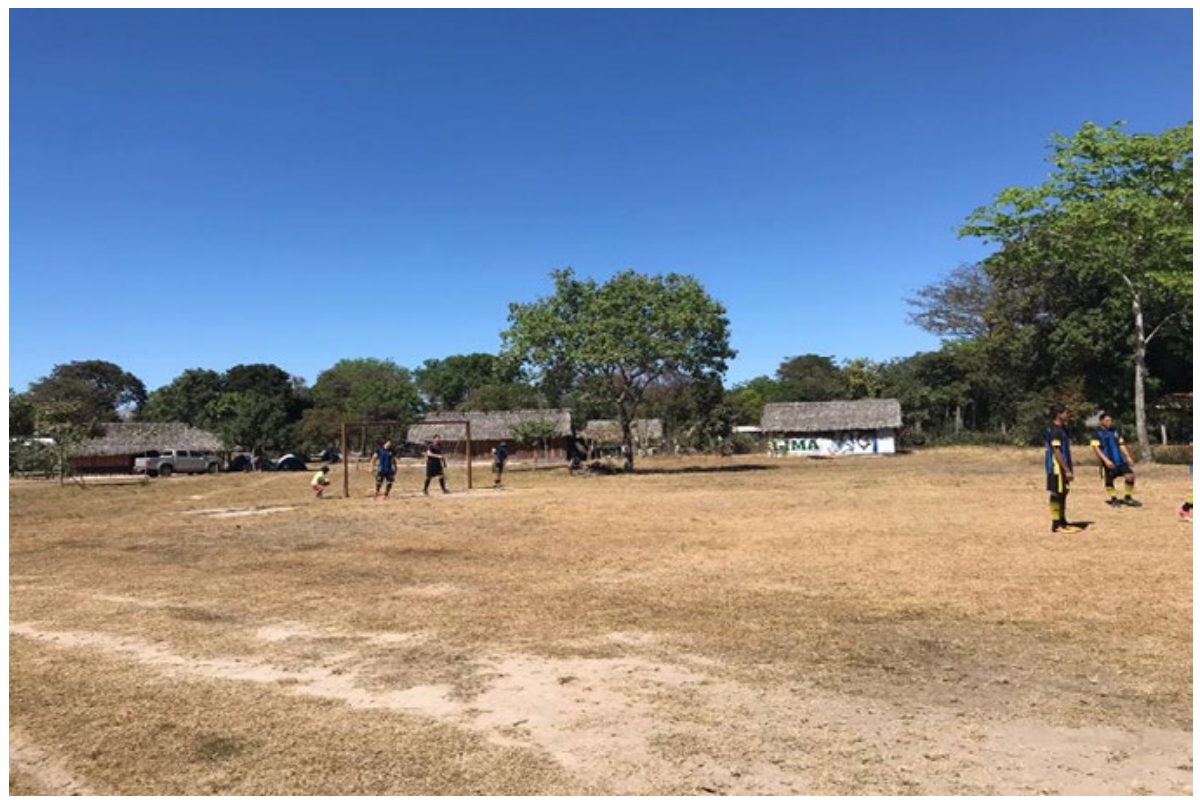

Fonte: Acervo Pukanu (2019).

Uma outra importante atividade da festa é a corrida com tora de madeira. Nesta atividade, os homens precisam percorrer uma certa distância com a tora, sem deixá-la cair no chão, assim vai passando para o próximo com muita calma. A título de esclarecimento, pela cultura Kanela, a tora representa muitas coisas, tais como os espíritos dos parentes que já morreram, além de união, resistência e valorização da própria cultuara, pois tem uma música própria para cada tipo de celebração.

O esporte, a dança e a pintura são meios de comunicação e interação com o mundo e comunidades, pois expressam sentimentos, emoções e também e um meio de resolver conflitos. No momento em que toda a sociedade retoma o debate acerca dos diretos indígenas, as escolas voltam a discutir as especificidades das políticas públicas voltadas para este público, tais como a demarcação, uso e conservação das terras indígenas e as formas de organização e de tratarem de temas fundamentais para a construção da autonomia, da liberdade e da cidadania. Cabe retomar a defesa de Arroyo (2007), pela valorização das manifestações culturais para proporcionar o fortalecimento das comunidades mais vulneráveis, como as do campo e os próprios indígenas.

Segundo o cacique da aldeia Nova Pukanu, por meio das festas culturais, o povo indígena fortalece suas identidades, aprende a viver em harmonia uns com os outros, fortalecendo a união dentro da comunidade. 
O ancião A afirma que, por meio da festa cultural, tanto os estudantes quanto toda comunidade podem aprender saberes culturais. Para ele, os professores da comunidade indígena precisam ter uma metodologia que atenda a realidade dos estudantes. Foram suas palavras sobre a relação entre cultura e escola: "Na época da colheita de coco babaçu podemos trabalha a ciências, com receitas de doces bolos e remédios, a química com o preparativo de sabão e cremes para o cabelo, no português com a escrita das palavras texto relacionados o tema, e na matemática com a quantidade de frutas e divisões, medidas receitas de bolos" (Ancião A). Ainda acrescenta a importância da arte de criar conforme a criatividade do povo, $\mathrm{o}$ que é fundamental para a fonte de renda.

Esse posicionamento comunga com o que pensa o ancião $C$, que reforçou que: "A educação é a base de todos os caminhos para o futuro de todas gerações, pois assim saberemos respeita a natureza e a cultura como um todo" (Ancião C). Percebe-se que esses experientes moradores evidenciam a relação possível entre a cultura indígena e a escola, entre a interação do homem e a natureza, além da convivência harmoniosa com todos da comunidade.

Já um outro entrevistado ressalta a necessidade de os professores serem da comunidade indígena para que essa interação cultural e escolar aconteça. Em suas palavras, ele afirmou: "É bom que os professores sejam de sua própria localidade, pois assim sabem desenvolve uma metodologia conforme a cultura e respeitando a realidade. Também temos que ter consciências de conviver respeitando a natureza, pois é nossa base para essência da vida" (Ancião E).

Nas palavras de um outro morador entrevistado sobre a festa: "Eu acredito quando festejamos libertaremos nossas emoções pelo bem esta da alma e da natureza e assim estamos repassando o sabe cultural para as crianças e não deixa perde a identidade de seu povo" (Ancião B).

Em similar perspectiva, outro entrevistado relata que: “A festa Amejkiim é muito importante para o resgate de nossa cultura que quase foi perdida e também com esses e vento cultural, adulto jovem e criança aprende conviver e respeitando as regras sociais de sua comunidade" (Ancião D).

Ao considerar os relatos das pessoas mais experientes, fica evidente que na escola é preciso valorizar os aspectos culturais para que todos vivam em paz, respeitando uns aos outros, porque dessa vida não se leva nada, mas podemos conviver e socializar nossos saberes culturais para as novas gerações, que são o futuro do povo indígena Kanela do Araguaia.

Nesse sentido, o registro da festa Amejkiim é propício e adequado, pois por ocorrer somente uma vez ao ano, é um importante registro e fonte de informações para ser explorado em outros momentos nas atividades escolares. Ao recordar esse momento, renovamos nossa alma e fortalecemos nossas raízes, precisamos de pouco para sobreviver em harmonia, pois a mãe natureza nos oferece tudo. Então não se pode destruí-la, pelo contrário, é preciso a conscientização das crianças para não serem consumistas, que utilizem e vivam 
somente com o necessário, assim se preserva a vida e a natureza, pois quanto menos consumo, menos destruição.

Desse modo, podemos observar que a escola propõe algumas ações que reforçam as ideias de educação cultural, inerente com as práticas da comunidade, no entanto, também apresenta algumas fragilidades que a distanciam da proposta de educação para os trabalhadores do campo construir sua emancipação e valorização da identidade camponesa. Por meio dos resultados coletados, foi possível constatar que existem muitos desafios acerca da construção de uma proposta educacional integrada aos anseios da comunidade e escola, o que também foi alertado por Lins, Figueiredo e Cavalcanti (2017), sobre a importância de reunir e explorar na educação do campo situações que envolvam a cultural e o social.

De um modo geral, as escolas indígenas precisamos para fortalecer a cultura indígena para assim dominar novos conhecimentos, ampliar sua autonomia e sermos construtores de uma sociedade mais justa, saudável e feliz. Isso corrobora o pensamento defendido por Campigoto, Schörner e Novak (2012), de que os festejos e ritos culturais são fenômenos ligado à cultura desse povo e por esse motivo merecem atenção da escola.

\section{CONSIDERAÇÕES FINAIS}

Este estudo teve o intuito de promover diálogos culturais com o Povo Kanela do Araguaia, por meio da compreensão da festa Amejikim, como uma ação educativa para abordar a intercultural idade. A forma com que o povo Kanela vive preciso ser respeitada, mesmo que nem sempre seja compreendida, principalmente pelo não indígena. Manifestações culturais, como a dança, por exemplo, permitem compreender saberem naturais e culturais, ou seja, diferentes maneiras de resolver um conflito, experimentando sensações, lidam com diferentes sentimentos e aprendem a cooperar vivendo em comunidade com um grupo social próprio indígena.

Nesse caso, o povo Kanela do Araguaia desenvolve suas danças considerando os diferentes contextos e situações que enfrentaram. Assim, o povo vai criando e recriando seus costumes, crenças, mitos e forma de vida. Ao compreender tais manifestações é possível, pois quando e realizado esse trabalho incluindo cultura e educação, os alunos e comunidade tem um desenvolvimento brilhante ao mesmo tempo que estuda se diverte com a arte, pinturas danças e rituais, pois e um aprendizado cultural, assim podese comunica com o corpo a mente, danças e rituais. pois é um processo muito importante na comunidade indígenas

Neste estudo apresentamos algumas reflexões sobre os desafios enfrentados pela escola e comunidade para a consolidação de uma educação que atenda aos anseios cultura indígena de quem vive no campo. Deveriam estar contidas dentro das práticas cotidianas questões referentes às particularidades 
da comunidade a qual está inserida. Por fim considero muito importante valorizar os valores cultura da cultura indígena, Kanela do Araguaia.

Este estudo foi de suma importância tanto para a vida profissional e pessoal desta pesquisadora, pois possibilitou compreender de perto a cultura do outro, bem como aproximar as manifestações culturais do povo Kanela do Araguaia aos estudantes, o que torna o aprendizado significativo, pois envolve a realidade local e contribui para o desenvolvimento de todos em meio a um ambiente agradável.

\section{REFERÊNCIAS}

ARROYO, Miguel Gonzalez. A Educação Básica e o Movimento Social do Campo. In: ARROYO, Miguel Gonzalez; CALDART, Roseli Salete; MOLINA, Mônica (org.) Por uma Educação do Campo. 3 ed. Petrópolis- RJ: Vozes, 2007.

CABALLERO, Indira Viana. Corpos que bebem, dançam e trabalham juntos: entre os ritmos da festa e do trabalho coletivo nos Andes peruanos. Tellus, v. 35, p. 59-84, 2018.

CAMPIGOTO, J. A.; SCHORNER, A.; NOVAK., J. Festas e ritos, memória e diversidade cultural. Canadian Journal of Latin American and Caribbean Studies, v. 37, p. 97-124, 2012.

GIL, Antônio Carlos. Como elaborar projetos de pesquisa. 5. ed. São Paulo: Editora Atlas, 2010.

LINS, Eunice Simões; FIGUEIREDO, Márcia Medeiros; CAVALCANTI, Dayanna Alves. Educação do Campo, mística e imaginário social: a importância da mística enquanto ação pedagógica. In: IV CONEDU Congresso Nacional de Educação, 2017, João Pessoa. Anais IV CONEDU V. 1, 2017. João Pessoa: Editora Realize, 2017. p. 1-9.

MELIÀ, Bartomeu. Diversidade cultural e educação intercultural. Tellus, v. 2, n. 3, p. 75-85, out. 2002.

RODRIGUES, Walace. O ambiente escolar e a valorização cultural indígena. Periferia (Duque de Caxias), v. 8, p. 106-122, 2016.

SOUZA, Kariny Teixeira. O faccionalismo Krahô-Kanela à luz da teoria da dádiva de Marcel Mauss. Ethos \& episteme (UFAM), v. IX, p. 92-102, 2009. 